\title{
Pulmonary rehabilitation in Canada: A report from the Canadian Thoracic Society COPD Clinical Assembly
}

\author{
Pat G Camp PT PhD ${ }^{1,2,3}$, Paul Hernandez MDCM FRCPC ${ }^{4}$, Jean Bourbeau MD FRCPC ${ }^{5}$, Ashley Kirkham BSc ${ }^{1}$, \\ Richard Debigare PT PhD ${ }^{6,7}$, Michael K Stickland PhD ${ }^{8,9}$, Donna Goodridge RN PhD ${ }^{10}$, Darcy D Marciniuk MD ${ }^{10}$, \\ Jeremy D Road BSc MD ${ }^{11}$, Mohit Bhutani MD ${ }^{8}$, Gail Dechman PT PhD ${ }^{12}$
}

PG Camp, P Hernandez, J Bourbeau, et al. Pulmonary rehabilitation in Canada: A report from the Canadian Thoracic Society COPD Clinical Assembly. Can Respir J 2015;22(3):147-152.

BACKGROUND: Pulmonary rehabilitation (PR) is a recommended intervention in the management of individuals with chronic lung disease. It is important to study the characteristics and capacity of programs in Canada to confirm best practices and identify future areas of program improvement and research.

OBJECTIVE: To identify all Canadian PR programs, regardless of setting, and to comprehensively describe all aspects of PR program delivery. The present article reports the results of the survey related to type of program, capacity and program characteristics.

METHODS: All hospitals in Canada were contacted to identify PR programs. A representative from each program completed a 175 -item online survey encompassing 16 domains, 10 of which are reported in the present article.

RESULTS: A total of 155 facilities in Canada offered PR, of which 129 returned surveys ( $83 \%$ response rate). PR programs were located in all provinces, but none in the three territories. Most (60\%) programs were located in hospital settings, $24 \%$ were in public health units and $8 \%$ in recreation centres. The national capacity of programs was estimated to be 10,280 patients per year, resulting in $0.4 \%$ of all Canadians with chronic obstructive pulmonary disease (COPD) and $0.8 \%$ of Canadians with moderate to severe COPD having access to PR. COPD, interstitial lung disease, and asthma were the most common diagnoses of patients. The majority of programs had at least four health care professionals involved; $9 \%$ had only one health care professional involved.

CONCLUSION: The present comprehensive survey of PR in Canada reports an increase in the number of programs and the total number of patients enrolled since the previous survey in 2005. However, PR capacity has not kept pace with demand, with only $0.4 \%$ of Canadians with COPD having access.

Key Words: Canada; Pulmonary rehabilitation; Survey

\section{La réadaptation pulmonaire au Canada : un rapport de l'assemblée clinique sur la MPOC de la Société canadienne de thoracologie}

HISTORIQUE : La réadaptation pulmonaire (RP) est une intervention recommandée pour la prise en charge des personnes atteintes d'une maladie pulmonaire chronique. Il est important d'étudier les caractéristiques et la capacité des programmes du Canada pour confirmer les pratiques exemplaires ainsi que de déterminer les futurs secteurs de recherche et d'amélioration des programmes.

OBJECTIF : Répertorier tous les programmes de RP au Canada, quel que soit leur lieu, et détailler tous les aspects de leur prestation. Le présent article rend compte des résultats du sondage sur les types de programmes, leur capacité et leurs caractéristiques.

MÉTHODOLOGIE : Les chercheurs ont communiqué avec tous les hôpitaux du Canada pour répertorier les programmes de RP. Un représentant de chaque programme a rempli un sondage virtuel de 175 questions dans 16 domaines, dont dix sont exposés dans le présent article.

RÉSULTATS : Au total, 155 établissements du Canada offraient la RP, dont 129 ont remis le sondage rempli (taux de réponse de $83 \%$ ). Des programmes de RP étaient offerts dans toutes les provinces, mais pas dans les trois territoires. La plupart des programmes (60\%) étaient offerts en milieu hospitalier, $24 \%$ dans des unités de santé publique et $8 \%$ dans des centres récréatifs. La capacité nationale des programmes était évaluée à 10280 patients par année. Ainsi, 0,4 \% de tous les Canadiens atteints d'une maladie pulmonaire obstructive chronique (MPOC) et 0,8\% des Canadiens atteints d'une MPOC modérée à grave avaient accès à la RP. La MPOC, les maladies pulmonaires interstitielles et l'asthme étaient les diagnostics les plus fréquents. La majorité des programmes comptaient sur la participation d'au moins quatre professionnels de la santé, mais dans $9 \%$ d'entre eux, un seul professionnel de la santé y participait.

CONCLUSION : Le présent sondage détaillé sur la RP au Canada fait état d'une augmentation du nombre de programmes et du total de patients inscrits par rapport au sondage précédent réalisé en 2005. Cependant, la capacité de RP ne répond pas à la demande, car seulement 0,4\% des Canadiens atteints d'une MPOC y ont accès.

the disease (2). Comprehensive PR programs include patient assessment, exercise training, education and psychosocial support. It is recommended for patients with chronic obstructive pulmonary disease (COPD) (2) and is beneficial for individuals with other chronic lung diseases, notably interstitial lung disease (ILD) (3), lung cancer (4), pulmonary arterial hypertension (5) and those who are pre- or post-lung transplantation $(6,7)$.
Dulmonary rehabilitation (PR) is a recommended, evidence-based and 1 comprehensive intervention for patients with chronic respiratory disease who are symptomatic and have difficulty with activities of daily living $(1,2)$. Pulmonary rehabilitation reduces dyspnea, optimizes functional status and reduces health care costs through improving patient self-management and stabilizing or reversing systemic manifestations of

${ }^{1}$ Centre for Heart Lung Innovation; ${ }^{2}$ Department of Physical Therapy, University of British Columbia; ${ }^{3}$ St Paul's Hospital, Providence Health Care, Vancouver, British Columbia; ${ }^{4}$ Department of Medicine, Dalhousie University, Halifax, Nova Scotia; ${ }^{5}$ Respiratory Epidemiology and Clinical Research Unit, Montreal Chest Institute, McGill University Health Centre, Montreal; ${ }^{6}$ Department of Rehabilitation, Université Laval; ${ }^{7}$ Centre de Recherche de l'Institut Universitaire de Cardiologie et de Pneumologie de Québec, Québec, Québec; ${ }^{8}$ Pulmonary Division, Department of Medicine, University of Alberta; ${ }^{9} \mathrm{GF}$ MacDonald Centre for Lung Health (Covenant Health), Edmonton, Alberta; ${ }^{10}$ Division of Respirology, Critical Care and Sleep Medicine, University of Saskatchewan, Saskatoon, Saskatchewan; ${ }^{11}$ Department of Medicine, University of British Columbia, Vancouver, British Columbia; ${ }^{12}$ School of Physiotherapy, Dalhousie University, Halifax, Nova Scotia

Correspondence: Dr Pat G Camp, UBC Centre for Heart Lung Innovation, St Paul's Hospital, 1081 Burrard Street, Vancouver, British Columbia V6Z 1Y6. Telephone 604-806-9144, e-mail pat.camp@hli.ubc.ca 


\section{TABLE 1}

\section{Pulmonary rehabilitation survey domains}

\begin{tabular}{ll}
\hline 1. Location and type of program & 9. Maintenance and follow-up \\
2. Barriers to access & 10. Program performance indicators \\
3. Capacity, completion & 11. Assessment and outcome measures \\
4. Diagnoses & 12. Aerobic exercise testing, prescription \\
5. Health care professionals & 13. Resistance exercise testing, prescription \\
6. Funding and resources & 14. Continuing professional development \\
7. Exercise training and education & 15. Research and network interests \\
8. Action plans, advance care & 16. Training opportunities \\
\hline
\end{tabular}

Domains 1 to 10 are reported in the present article

Despite these benefits, access to PR in Canada and elsewhere remains low. In 1999, Brooks et al (8) reported on a Canadian survey of 36 PR programs and noted the low capacity of these programs to provide care for the patient population. This survey was repeated in 2005 (9) and, although the number of facilities offering PR programs had increased to 60 , it was estimated that only $1.2 \%$ of the COPD population had access to PR in their community. At that time, PR was not available in the Canadian territories, Prince Edward Island or Newfoundland and Labrador. Similarly, a 2004 survey of programs in the United Kingdom reported that fewer than $1 \%$ of COPD patients had access to PR (10).

Although it is just 10 years since the last Canadian survey of PR programs was conducted, there are several areas that warrant an update. The 2005 survey targeted hospitals with $>250$ beds, rehabilitation centres and rehabilitation programs identified by the Canadian Lung Association and provincial lung associations; however, PR services are often located in community-based facilities and smaller hospitals. Therefore, the 2005 survey may have underestimated the availability of PR in Canada, particularly in smaller communities. In addition, several provinces are exploring the use of novel methods of delivering PR, including home-based programs or telehealth (11), and more information about these types of programs is needed. Finally, a new survey that identified all programs in Canada could lead to the creation of a national registry of programs to enable the continuing professional development of PR health care professionals.

Results from other PR surveys in the United States (12) and Europe (13) have been recently published; however, those surveys were brief (12 to 15 questions), had few respondents from Canada, and did not describe all aspects of PR delivery and care. Therefore, the Canadian Thoracic Society COPD Clinical Assembly aimed to identify all Canadian PR programs, regardless of setting, and to comprehensively describe all aspects of PR program delivery. The present article reports the results of the survey related to type of program, capacity and program characteristics.

\section{Study team}

\section{METHODS}

The study team consisted of members of the Canadian Thoracic Society COPD Clinical Assembly. The COPD Clinical Assembly has representation from the Canadian Thoracic Society and the Canadian Respiratory Health Professionals, which are the two health professional societies of the Canadian Lung Association.

\section{Survey development}

To create the current survey, questions from other surveys of PR were used $(9,12,13)$, but the scope of the survey was expanded to include 16 domains (Table 1). These domains included questions on program delivery (eg, type of program, frequency of sessions, duration); patient access and completion (eg, capacity, referral source, wait lists, completion rates and barriers to access); resources (eg, funding, equipment); health care professionals involved; aerobic and resistance exercise testing, prescription and outcomes; education topics and the use of certified respiratory educators; continuing professional development; and health care professional training needs. The online survey was created using FluidSurveys (Fluidsurveys, Canada) and had >175 items, with several items having multiple components. The survey was initially tested by members of the COPD Clinical Assembly and by four staff members of PR programs, and was subsequently revised based on their feedback. The estimated time to complete the survey was $45 \mathrm{~min}$. The full survey can be found at <www.respiratoryguidelines.ca/2015-cts-report-pulmonary-rehabilitation>.

\section{Program identification and recruitment}

Canadian PR programs were identified through a variety of sources. The lists of PR programs were obtained from the Canadian Lung Association (www.lung.ca/respDB/search-pulmonary-rehabilitation_e. php) and the COPD Patient Network (www.copdcanada.ca) websites, as well as website searches using Google and Internet Explorer. Search terms included the words "pulmonary rehabilitation", "respiratory rehabilitation", "exercise programs", "chronic lung disease", "COPD" and "provinces". The respiratory therapy and physical therapy departments of all hospitals listed in Scott's Health Care Directory (14) were telephoned to enquire whether a PR program existed in their facility. In Quebec, the registry of the Régie de l'assurance maladie Québec, which identifies all PR programs in the province, was used. During all telephone contacts, program staff were asked whether they knew of any PR programs in their community or in neighbouring communities.

Once a potential program was identified, each program representative was contacted to obtain basic information and confirm eligibility for the survey. PR was defined as a program that focused on chronic lung disease patients and included assessment and more than one session of aerobic exercise. Generic chronic disease management or wellness programs that enrolled participants with any chronic disease, including respiratory disease, for the purposes of exercise and education support were not considered to be PR for the purposes of the present survey. Inpatient acute care rehabilitation programs for individuals with exacerbations of chronic respiratory disease were not included; however, inpatient programs for patients with chronic respiratory disease were included. Once a program was verified as being eligible for the survey, the key contact person for the program supplied their e-mail for ongoing contact.

\section{Procedure}

Ethics approval for the current study was obtained from the Providence Health Care/University of British Columbia Research Ethics Board (Certificate H12-02380). The study was funded, in part, by the Canadian Thoracic Society.

Each program representative was invited to participate through an introductory e-mail that outlined the purpose of the survey along with a letter of consent, the survey link and a unique alphanumerical password to preserve anonymity. Follow-up e-mails were sent approximately four weeks after the initial e-mail, and then a follow-up telephone call was made if there was no response to the e-mails. Each institution answered one survey. If an institution had multiple sites or different program types (ie, hospital based or telehealth), additional survey links were issued. Survey responses were downloaded into a spreadsheet. Two survey completion reminders were also sent. Program representatives were contacted by telephone or e-mail if there were missing answers or the need for clarification to a response provided.

\section{Data analysis}

The present article provides the results related to domains 1 to 10 of the survey (location and type of program; barriers to access; health care professionals; capacity, frequency, duration; diagnoses; funding and resources; exercise and education; action plans, advance care plans; maintenance and follow-up; and program performance indicators).

Program locations were mapped using the open access maps from the Government of Canada (15). SAS version 9.4 (SAS Institute Inc, USA) and Microsoft Excel (Microsoft Corporation, USA) were 


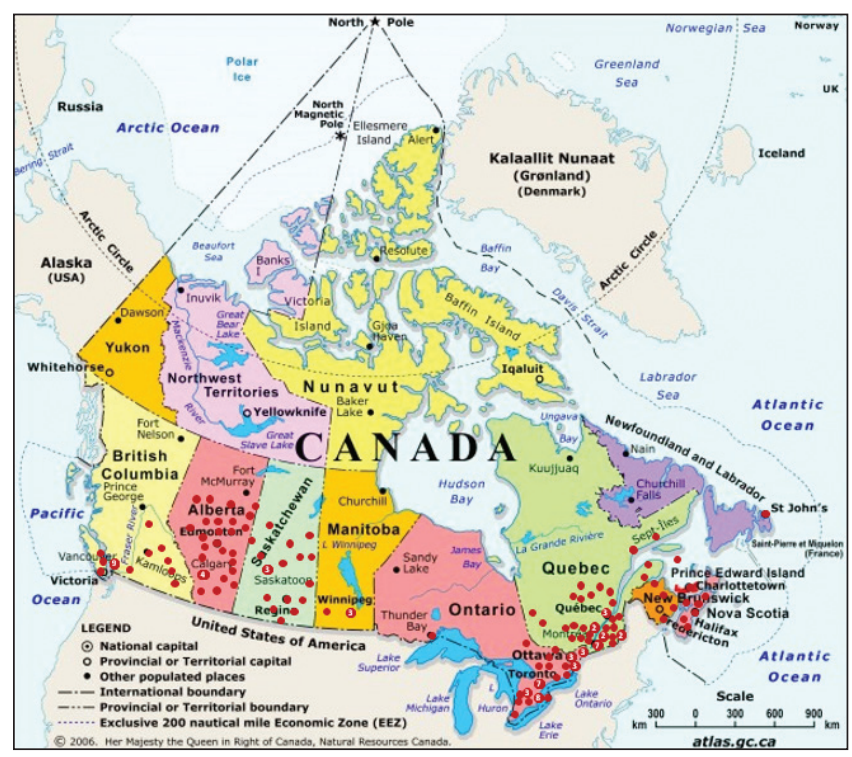

Figure 1) Map of Canada indicating all identified programs (15)

used for the statistical analyses. Counts and proportions, means and SDs, and medians and interquartile ranges (IQRs) were calculated where appropriate.

\section{RESULTS}

Program location and type, capacity and barriers to access In total, 155 PR programs in Canada were identifed and sent surveys; responses were received from 129 (83\% response rate). At least one PR program was located in each Canadian province, but no programs were identified in the three territories. Figure 1 is a map of Canada with all identified programs. The majority of programs followed the Canadian population distribution and were located near the Canada/ United States border. However, Alberta and Saskatchewan had programs distributed throughout the provinces. Most programs (60\%) were hospital-based outpatient programs, although approximately $24 \%$ were located in public health units offsite from a hospital location. Eight percent of programs were located in recreation centres (Table 2).

The mean $( \pm$ SD) number of individuals enrolled in PR was $84 \pm 98$ per program per year. Fifty percent of programs enrolled $<50$ individuals per year. Based on these figures, the national capacity of Canadian PR programs was estimated to be 10,280 individuals per year. Respondents reported that the top three barriers to increasing access to PR were the lack of staff time to deliver PR (38\%), limited effectiveness of current referral systems (19\%), and the travel distance and/or time for patients (10\%) (Figure 2).

Program completion rate was high, with 110 (87\%) programs reporting that $>60 \%$ of patients completed PR (Table 2). Forty-seven percent of programs reported that they tracked the reasons why patients did not complete PR. Disease exacerbation was the number one reason for noncompletion, reported by $50 \%$ of programs, followed by other health issues (28\%) and transportation challenges (12\%).

\section{Diagnosis}

Figure 3 indicates the proportion of programs that admit various respiratory-related conditions. As expected, $100 \%$ of the programs admitted patients with COPD. Individuals with asthma and ILD were admitted by $75 \%$ and $71 \%$ of programs, respectively. Patients with other respiratory-related conditions, such as cystic fibrosis, chest wall abnormalities, neuromuscular disorders or post-acute respiratory distress syndrome were infrequently admitted to PR.

Health care professionals

Most programs had at least four health care professionals involved with the program (median 4, IQR 3 to 6). Nine percent of programs
TABLE 2

\section{Program characteristics $(n=129)$}

\begin{tabular}{|c|c|}
\hline Type of program & n (\%) \\
\hline Hospital-based outpatient & $78(60)$ \\
\hline Health centre & $31(24)$ \\
\hline Community based & $10(8)$ \\
\hline Hospital-based inpatient & $5(4)$ \\
\hline Telehealth & $3(2)$ \\
\hline Home based & $2(2)$ \\
\hline \multicolumn{2}{|l|}{ Completion rates, $\%$ of patients } \\
\hline $81-100$ & $52(41)$ \\
\hline $61-80$ & $58(46)$ \\
\hline $41-60$ & $13(10)$ \\
\hline $21-40$ & $3(2)$ \\
\hline $0-20$ & $1(1)$ \\
\hline \multicolumn{2}{|l|}{ Funding sources* } \\
\hline Hospital or institution & $50(39)$ \\
\hline Regional Health Authority & $48(37)$ \\
\hline Provincial ministry of health & $34(26)$ \\
\hline Participant fee & $15(12)$ \\
\hline Other (pharmaceutical company, private donation) & $18(14)$ \\
\hline \multicolumn{2}{|l|}{ Program resources } \\
\hline Exercise room/gym & $121(94)$ \\
\hline Education classroom & $112(87)$ \\
\hline Clinic examination room & $68(53)$ \\
\hline Staff office & $97(75)$ \\
\hline Defibrillator or code blue response & $103(80)$ \\
\hline Telemetry for cardiac or oxygen saturation monitoring & $68(52)$ \\
\hline Oxygen - wall source & $38(29)$ \\
\hline Oxygen - tanks & $110(85)$ \\
\hline \multicolumn{2}{|l|}{ Aerobic exercise equipment $(n=114)$} \\
\hline Cycle ergometer & $89(78)$ \\
\hline Treadmill & $89(78)$ \\
\hline Hallway for walking & $82(72)$ \\
\hline Arm ergometer & $69(61)$ \\
\hline Stair climbing & $69(61)$ \\
\hline Elliptical trainer & $15(13)$ \\
\hline Schwinn ${ }^{T M}$ cycle & $18(16)$ \\
\hline Rowers & $12(11)$ \\
\hline \multicolumn{2}{|l|}{ Program performance indicators } \\
\hline Participant satisfaction & $94(73)$ \\
\hline Enrollment rate & $66(51)$ \\
\hline Completion rate & $63(49)$ \\
\hline Wait list time & $62(48)$ \\
\hline Drop out rate & $41(32)$ \\
\hline Program cost & $35(27)$ \\
\hline Equipment and consumables cost & $26(20)$ \\
\hline Cost per patient & $25(19)$ \\
\hline Facility costs & $24(19)$ \\
\hline Other & $16(12)$ \\
\hline None of the above & $11(9)$ \\
\hline
\end{tabular}

*Programs could select more than one funding source

had only one individual involved in program delivery. Figure 4 shows the proportion of health care professionals according to discipline. Respiratory therapists were the most represented health care discipline (82\%), followed by dietitians (68\%) and physiotherapists (67\%). Fewer than $50 \%$ of programs reported having a respirologist closely involved with the program.

Referrals, funding and resources

Programs received referrals from a variety of sources, although most programs $(85 \%)$ indicated that they received referrals from respirologists 


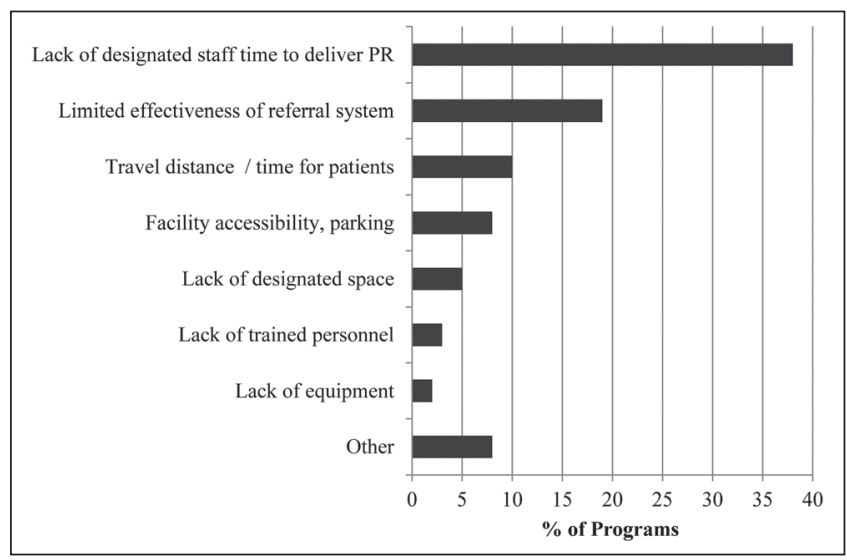

Figure 2) Program-reported barriers to increasing access to pulmonary rehabilitation $(P R)$

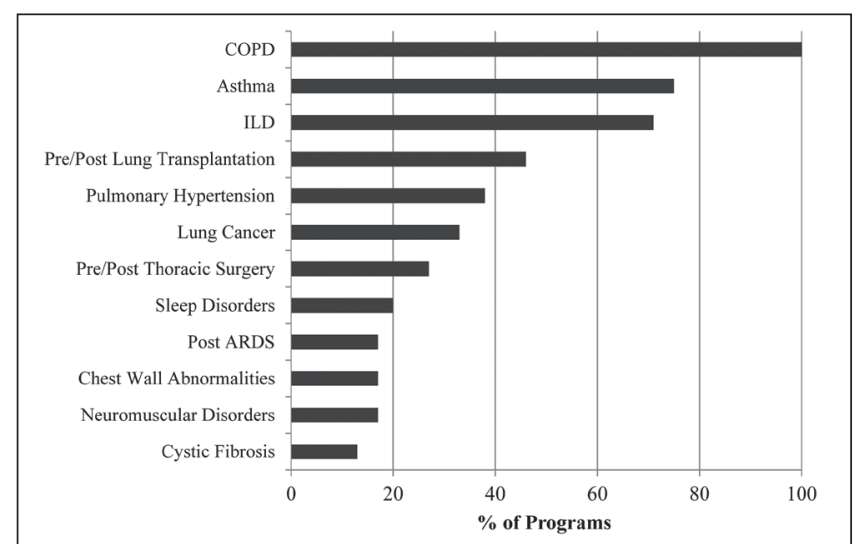

Figure 3) Percentage of programs who report admitting patients with different respiratory-related diagnoses. ARDS Acute respiratory distress syndrome; COPD Chronic obstructive pulmonary disease; ILD Interstitial lung disease

or family physicians. Other common referral sources were respiratory therapists (referred patients to $52 \%$ of programs), physiotherapists (referred patients to $32 \%$ of programs) and patients (self-referral to $52 \%$ of programs). Once referred, wait list times to start PR were variable. Fifty-five percent of programs had a waitlist time of $\geq 7$ weeks, and $22 \%$ had a wait list time of $\geq 12$ weeks. Funding for PR came from a variety of sources, including hospitals, health authorities, provincial ministries of health, participant fees, pharmaceutical companies and local donations (Table 2). Seventy-five percent of programs identified only a single funding source.

Most programs had an exercise gym and other equipment for PR program delivery (Table 2). Of note, $10 \%$ of programs did not have any access to supplemental oxygen. Not all programs had access to a defibrillator or 'code blue' response team. Eighty-nine percent of programs had a cycle ergometer and/or a treadmill for exercise, whereas elliptical trainers and rowers were less available.

\section{Exercise and education components}

Most (83\%) programs provided two to three exercise sessions per week, with a median time of $1.5 \mathrm{~h}$ per exercise session. The duration of the programs ranged from one week to programs that did not discharge their patients; $44 \%$ of programs were six to eight weeks in duration and $37 \%$ were nine to 12 weeks in duration. In programs that discharged patients, the median total number of exercise classes per program session was 20 (IQR 16 to 24).

Figure 5 illustrates the different education topics offered by the PR programs. Overall, there was consistency in the topics offered

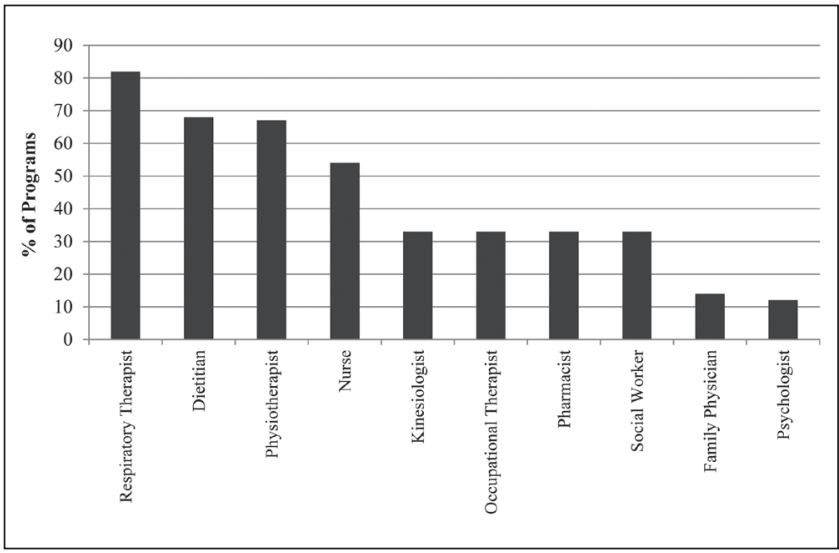

Figure 4) Health care professionals involved in pulmonary rehabilitation programs

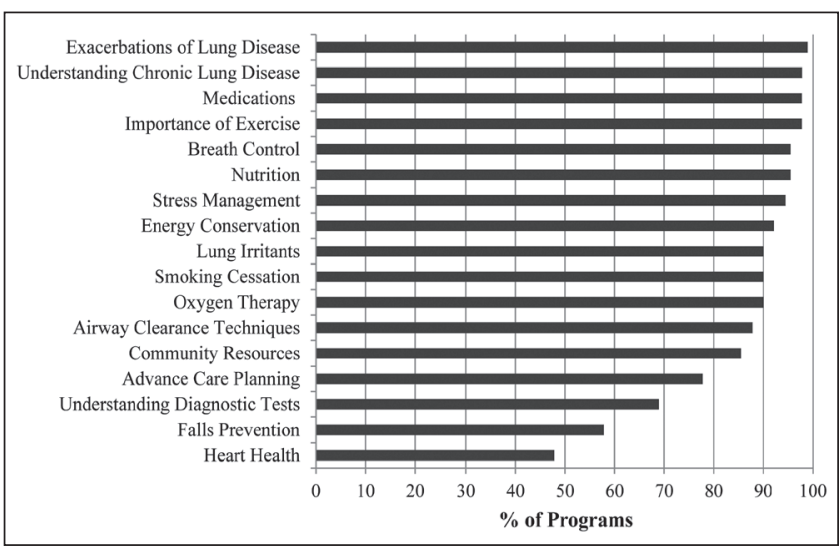

Figure 5) Education topics provided by programs

by programs because $>80 \%$ offered education in topics considered essential in PR, including understanding chronic lung disease, medications, breathing control and oxygen therapy. The topics least discussed were heart health (provided by $48 \%$ of programs); falls prevention (provided by $58 \%$ of programs); understanding diagnostic tests (provided by $69 \%$ of programs); and advance care planning (provided by $78 \%$ of programs). Seventy-five percent of programs had a certified respiratory educator associated with the program who provided at least one educational session.

Regarding the use of written action plans, advance care directives, and written 'code status' orders, $78 \%$ of programs reported that patients receive a written action plan; $23 \%$ of programs reported that patients have a written advance care directives; and $16 \%$ of programs report that patients have a written code status order.

Follow-up and maintenance components

Seventy percent of programs provided a follow-up assessment after discharge. Of these, $63 \%$ assessed exercise, $71 \%$ assessed knowledge and dyspnea, $62 \%$ assessed health-related quality of life, and $28 \%$ assessed pulmonary function and health care utilization. Forty-seven percent of programs offered an ongoing exercise maintenance class; of these, $42 \%$ (24 programs) also offered ongoing education sessions.

\section{Program performance indicators}

Table 2 itemizes the program performance indicators collected by the PR programs. Participant satisfaction was the most commonly collected indicator $(73 \%)$, followed by completion rate and wait list time (49\% and 48\%, respectively). Nine percent of programs did not collect data on any program performance indicator. 


\section{DISCUSSION}

The present article reports the third national PR survey conducted in Canada. Previous surveys $(8,9)$ provided details on program characteristics and highlighted the extremely low total capacity of PR programs to enrol individuals with chronic lung disease who need this care. In the present survey, we contacted all hospitals to identify programs. We also contacted rehabilitation programs identified by the Canadian Lung Association and extended the search to include PR programs in public health units and recreation centres. We identified 155 facilities that offered PR programs, an increase from 60 facilities in 2005. The national capacity of the programs continues to be low, with just over 10,000 individuals admitted annually. The 2009. 2011 Canadian Health Measures Survey estimated that 13\% of Canadians between 35 and 79 years of age have COPD; 7\% in that age group have at least moderate disease, as indicated by spirometry (16). Based on 2011 census measures of the Canadian population (17), the prevalence of COPD is estimated to be 2.5 million adults, with an estimated 1.3 million having moderate disease. Therefore, based on these estimates and our calculation of the total capacity of programs, approximately $0.4 \%$ of all Canadians with COPD and $0.8 \%$ of Canadians with moderate to severe COPD have access to a PR program.

Although the total number of programs and absolute number of patients admitted has increased, our estimated capacity is much less than the $1.2 \%$ reported by Brooks et al (9) in 2007. One reason for this is that the number of Canadians estimated to have a diagnosis of COPD has increased (18) and the number of available programs cannot meet this demand. In addition, the COPD prevalence estimates in the previous reports were based on the Canadian Community Health Survey, which uses self-reports of diagnosis to estimate prevalence, and is considered to be an underestimate of the true prevalence of COPD. The Canadian Health Measures Survey conducts field spirometry tests and, therefore, its estimates of COPD prevalence are likely more accurate. The low capacity of PR in Canada is in sharp contrast to cardiac rehabilitation, where a recent position paper (19) by the Canadian Association of Cardiac Rehabilitation and the Canadian Cardiovascular Society noted that $34 \%$ of high-risk cardiac patients were referred to Ontario cardiac rehabilitation programs. The authors also noted that in New Brunswick, 19\% of eligible cardiac patients complete rehabilitation.

Although most programs continue to be located in acute or ambulatory care hospitals, there are now telehealth-, home-, community centre- and health unit-based programs. This is in contrast to PR delivery in the United States, where the majority of American Association of Cardiovascular and Pulmonary Rehabilitation-accredited programs are hospital-based (95\%) with only $5 \%$ of programs in alternative locations (12). While the diversity of program locations in Canada likely increases the capacity of $\mathrm{PR}$ in smaller communities, there is little research investigating the safety and effectiveness of PR outside larger hospital settings where there is access to multidisciplinary teams, extensive equipment and specialist care. For example, we found that $10 \%$ of programs did not have available supplemental oxygen and only $80 \%$ had access to a defibrillator or 'code blue' response team. However, research on PR delivery outside of hospital settings is emerging. Stickland et al (11) compared telehealth PR with traditional PR in Alberta and reported similar benefits in exercise and quality of life outcomes in both groups. Maltais et al (20) reported similar patient benefits following PR delivered in a home setting compared with PR delivered in a supervised health care setting. PR offered via telehealth, community centres or health units, with support from larger centres, may offer an attractive solution for some communities, especially as one in 10 programs in Canada are staffed by just one health care professional. Although there are no Canadian-specific guidelines for PR program delivery, the American Association of Cardiovascular and Pulmonary Rehabilitation require at least two health care professionals to be present during PR exercise sessions (21). However, with more health unit, telehealth and home programs emerging, it is important to consider how supervision will be performed in those settings. There may be a need for enhanced screening of patients to ensure the safety of exercise away from a hospital setting.

Patients with ILD were admitted to most programs in Canada. This is similar to the findings reported by Spruit et al (13) and Garvey et al (12), who noted that the proportion of patients with ILD was as high as or higher than those with asthma. Despite this, there are no specific PR guidelines for individuals with ILD. Emerging evidence indicates that PR is beneficial and has long-term effects in individuals with ILD (3). However, these patients often have severe hypoxemia with exercise, and may have concomitant pulmonary hypertension, which makes exercise safety and ongoing research in this area a priority.

There was consistency in the education topics offered by PR programs and new topics such as falls prevention and heart health are emerging. This may be in response to the growing evidence on the impact of multimorbidities in COPD (22) and other chronic lung diseases. It was encouraging to observe the large proportion of programs that included written action plans; however, although advance care planning was discussed by $78 \%$ programs in the education sessions, only $23 \%$ of programs reported that their participants had an advance care directive in place. Continued professional development to enable PR staff to assist patients with this important aspect of chronic disease management may be necessary to bridge this gap.

There were several strengths and limitations of the present study. A key strength was the careful identification of all PR programs in Canada, including those located in smaller hospitals, public health units or recreation centres. It is possible that we did not identify all PR programs in recreation centres because we relied on word-ofmouth and Internet searches to identify programs in those settings. Another strength was the very high response rate of $83 \%$, which is in contrast to the rate of $13 \%$ reported by Garvey et al (12) in the United States study. Therefore, although the absolute number of PR programs was low compared to that reported by Garvey et al (12) and Spruit et al (13), we are confident that our results are generalizable to all PR programs in Canada. This survey was very comprehensive and covered the key aspects of PR (the first section of which is reported here). However, all the information we collected was at the program level. We did not collect any patient-level data and cannot comment on the effectiveness of programs in the Canadian setting. Future work should focus on an audit of programs to investigate whether programs use evidence-based best practices for program delivery and generate expected patient benefits. Finally, our initial inclusion criteria included programs that offered more than one supervised exercise session, so that home-based PR programs would not be excluded. Although the Canadian Thoracic Society's PR guidelines recommend 12 sessions of supervised exercise, there are no specific guidelines regarding the number of supervised sessions required for home-based or telehealth programs. Future recommendations for supervision of exercise may need to be reconsidered as telehealth and alternative modes of PR evolve.

\section{CONCLUSIONS}

We conducted a comprehensive study of PR programs in Canada and found that although the actual capacity of PR has increased since 2007, it has not kept pace with the demand for this care for COPD and other chronic respiratory disease patients, with only $0.4 \%$ of Canadians with COPD having access. Encouragingly, the survey demonstrates that PR is moving into non-hospital-based settings, which may improve access to programs in the future; more research is needed to identify best practices in these settings.

ACKNOWLEDGEMENTS: The authors acknowledge Christen Chan, Valerie Chabot and Bruno Lemire for assistance with survey development and participant recruitment. Dr Pat Camp is a Michael Smith Foundation for Health Research Scholar. 


\section{REFERENCES}

1. Marciniuk DD, Brooks D, Butcher S, et al. Optimizing pulmonary rehabilitation in chronic obstructive pulmonary disease - practical issues: A Canadian Thoracic Society clinical practice guideline. Can Respir J 2010;17:159-68.

2. Spruit MA, Singh SJ, Garvey C, et al. An official American Thoracic Society/European Respiratory Society statement: Key concepts and advances in pulmonary rehabilitation. Am J Respir Crit Care Med 2013;188:e13-64.

3. Ryerson CJ, Cayou C, Topp F, et al. Pulmonary rehabilitation improves long-term outcomes in interstitial lung disease: A prospective cohort study. Respir Med 2014;108:203-10.

4. Coats V, Maltais F, Simard S, et al. Feasibility and effectiveness of a home-based exercise training program before lung resection surgery. Can Respir J 2013;20:e10-6.

5. Mereles D, Ehlken N, Kreuscher S, et al. Exercise and respiratory training improve exercise capacity and quality of life in patients with severe chronic pulmonary hypertension. Circulation 2006;114:1482-9.

6. Wickerson L, Mathur S, Brooks D. Exercise training after lung transplantation: A systematic review. J Heart Lung Transplant 2010;29:497-503.

7. Langer D, Burtin C, Schepers L, et al. Exercise training after lung transplantation improves participation in daily activity: A randomized controlled trial. Am J Transplant 2012;12:1584-92.

8. Brooks D, Lacasse Y, Goldstein RS. Pulmonary rehabilitation programs in Canada: National survey. Can Respir J 1999;6:55-63.

9. Brooks D, Sottana R, Bell B, et al. Characterization of pulmonary rehabilitation programs in Canada in 2005. Can Respir J 2007;14:87-92.

10. Yohannes AM, Connolly MJ. Pulmonary rehabilitation programmes in the UK: A national representative survey. Clin Rehabil 2004;18:444-9.

11. Stickland M, Jourdain T, Wong EY, et al. Using Telehealth technology to deliver pulmonary rehabilitation in chronic obstructive pulmonary disease patients. Can Respir J 2011;18:216-20.
12. Garvey C, Fullwood MD, Rigler J. Pulmonary rehabilitation exercise prescription in chronic obstructive lung disease: US survey and review of guidelines and clinical practices.J Cardiopulm Rehabil Prev 2013;33:314-22.

13. Spruit MA, Pitta F, Garvey C, et al. Differences in content and organisational aspects of pulmonary rehabilitation programmes. Eur Respir J 2014;43:1326-37.

14. Business Information Group. Scott's Canadian Medical Directory, 2004 Edition. Toronto: Current Publications, 2004.

15. Natural Resources Canada. Map of Canada, 2006.

16. Canadian Health Measures Survey, 2009-2011. Catalogue No. 82-626-X, Ottawa: Statistics Canada, April 2013.

17. Statistics Canada. Census Profile 2011. < www12.statcan.gc.ca/ census-recensement/2011/dp-pd/prof/index.cfm?Lang=E > (Accessed November 19, 2014).

18. Statistics Canada. Chronic Obstructive Pulmonary Disease by Age Group and Sex, 2011-2013. <www.statcan.gc.ca/tables-tableaux/ sum-som/101/cst01/health104a-eng.htm > (Accessed November 19, 2014).

19. Grace SL, Chessex C, Arthur H, et al. Systematizing inpatient referral to cardiac rehabilitation 2010: Canadian Association of Cardiac Rehabilitation and Canadian Cardiovascular Society joint position paper endorsed by the Cardiac Care Network of Ontario. Can J Cardiol 2011;27:192-9.

20. Maltais F, Bourbeau J, Shapiro S, et al. Effects of home-based pulmonary rehabilitation in patients with chronic obstructive pulmonary disease: A randomized trial. Ann Intern Med 2008;149:869-78.

21. American Association of Cardiovascular and Pulmonary Rehabilitation. Guidelines for Pulmonary Rehabilitation Programs/American Association of Cardiovascular and Pulmonary Rehabilitation. 3rd edn. Champaign: Human Kinetics, 2004.

22. Faner R, Cruz T, Lopez-Giraldo A, et al. Network medicine, multimorbidity and the lung in the elderly. Eur Respir J 2014; $44: 775-88$. 


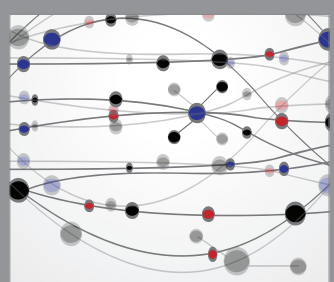

The Scientific World Journal
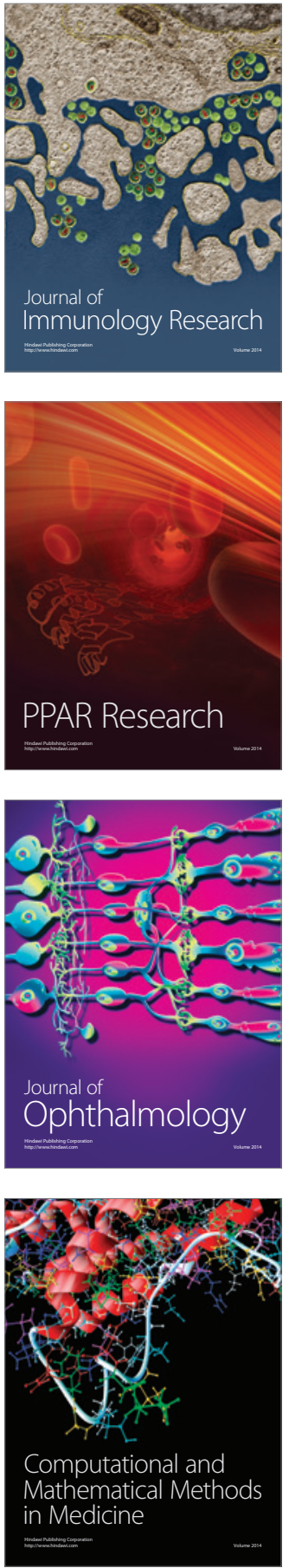

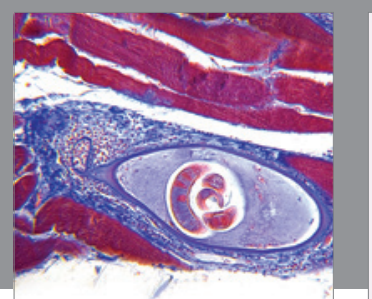

Gastroenterology Research and Practice

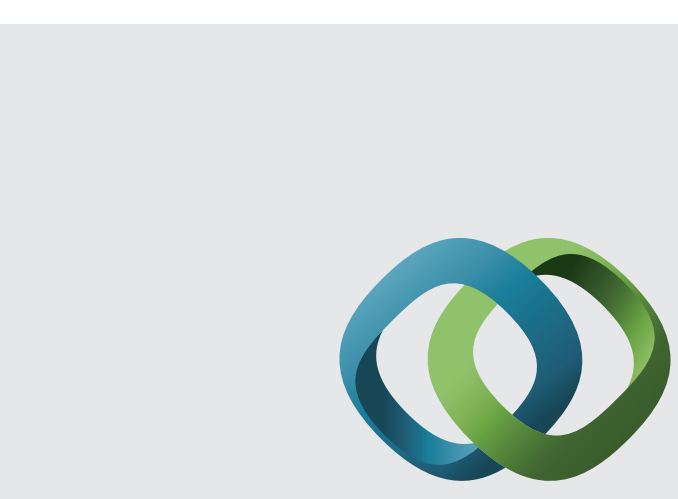

\section{Hindawi}

Submit your manuscripts at

http://www.hindawi.com
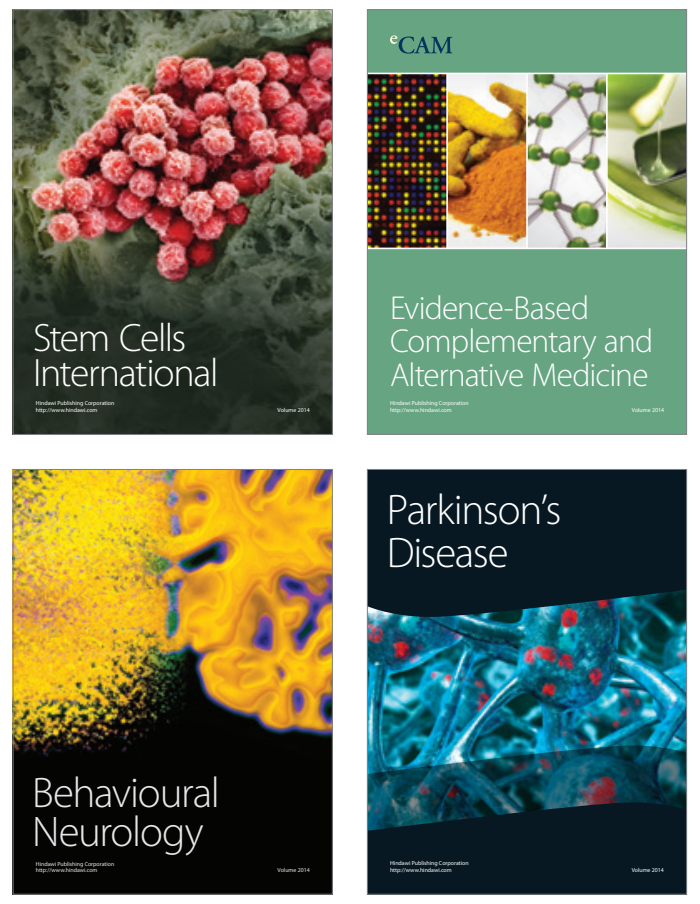
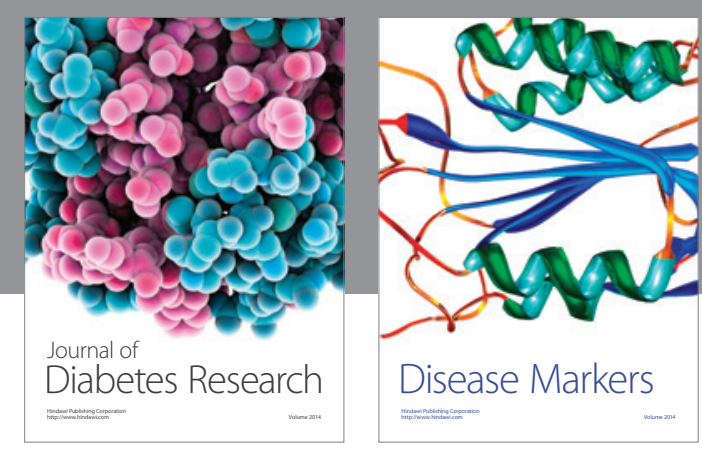

Disease Markers
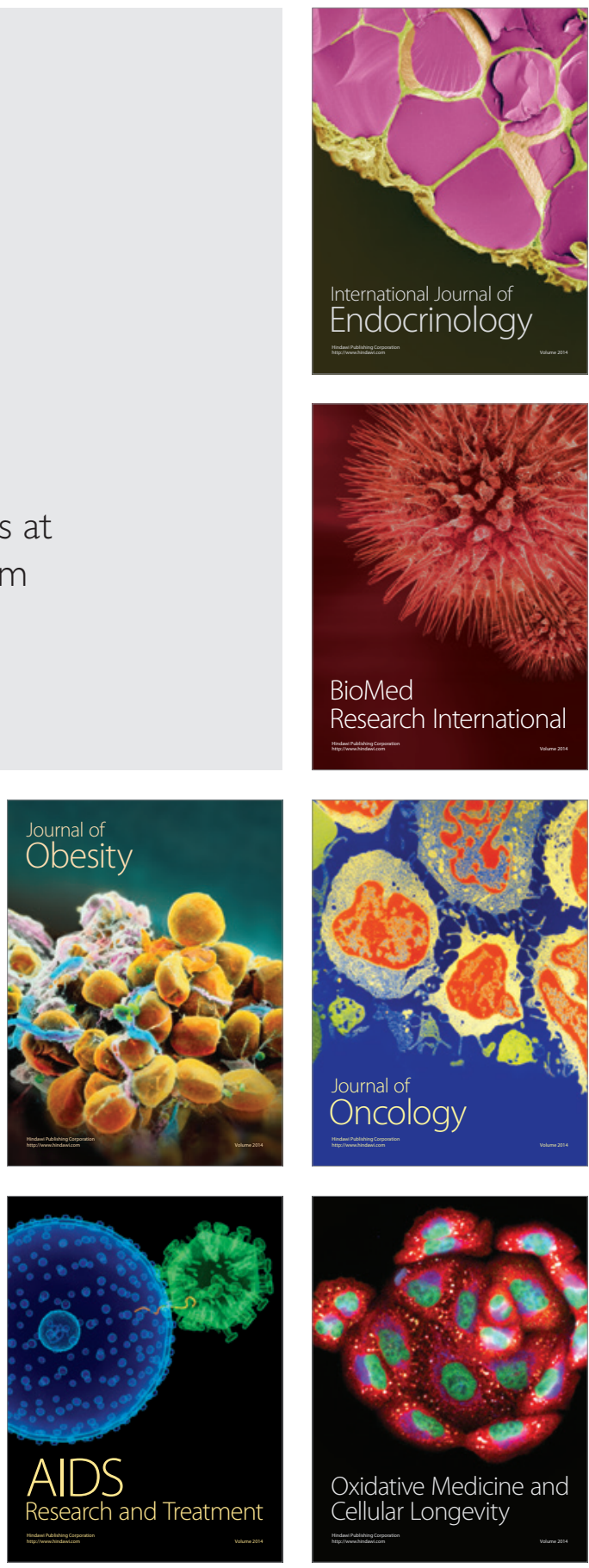